\title{
Evolutionary Change in Product Management: Experiences in the Car Rental Industry
}

William J. Carroll

RiCHARD C. GRIMES

\author{
The Hertz Corporation \\ 225 Brae Boulevard \\ Park Ridge, New Jersey 07656-0713 \\ Decision Focus Incorporated \\ 650 Castro Street, Suite 300 \\ Mountain View, California 94041-2055
}

Car rental companies offer customers various combinations of car types, rental periods, and pickup and return locations, as well as temporary insurance and refueling options. Hertz developed its yield management system (YMS) to help decide the availability of these combinations of products over time. The YMS integrates information management technology, sophisticated operations research techniques, and information from existing Hertz decision support models that solve the closely-related problems of pricing, fleet planning, and fleet deployment.

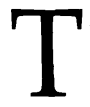

he car rental business began in 1918 .

It was a simple business. Local operators provided a set of standard cars to individuals for a fixed per-day charge plus a per-mile charge. Over time that simple proposition became more complicated. In the 1930s, Hertz created the concept of rent-it-here and leave-it-there. By the 1950s, rental car companies made available multiple types of cars at airports, railroad stations, hotels, and other locations. In the 1970s, companies distributed the rates and availabilities for car rental products (a product is a specific combination of car type, temporary insurance, pickup location, return location, and length of keep) through internal and external computerized reservations systems. In the 1990s, they began using price and yield management systems that allow them to control the price and availability of these products.

In the US, the car rental industry is divided into the travel, lease, and replacement markets. The largest of these is the travel market, and Hertz is a major player in that market. Hertz is a wholly owned

\footnotetext{
Copyright (C) 1995, Institute for Operations Research 


\section{CAR RENTAL}

subsidiary of the Ford Motor Company. In the US, it has 1,300 locations and a fleet of 250,000 .

Over the past decade, the travel-related car rental market has changed dramatically. Deregulation of the airlines changed the number and mix of customers renting cars. The advent of discount air fares in 1977 increased the number of customers needing rental cars and the proportion of leisure renters. Computerized reservation systems (CRS), such as SABRE and APOLLO, facilitated their booking cars and comparing prices among firms.

Initially, the major car rental firms were Hertz, Avis, National, and Budget. The major firms expanded their base of rentals through the commercial market. They contract with large corporations to provide car rental services to their employees for a fixed-per-day price across all or most locations for a given period of time. The fees normally vary based upon volume and can include alternate levels of insurance protection. Prices by class of vehicle and location are set by contract for a period of time and cannot be managed upward in periods when demand exceeds car supply.

With increased airline competition in the 1980s, more nonaffiliated, small business and leisure customers entered the market. Leisure-oriented firms, such as Alamo and Dollar, took advantage of these changes. These firms relied on low prices, leisure locations, travel agents, and tour operators to gain market prominence.

A major factor in changing the types of firms serving the car rental market was the growing importance of new global distribution channels - computerized airline reservation systems - through which custom- ers can book car rentals. Working with travel agents, the newer car rental firms attracted customers by displaying their low prices prominently in CRS "shoppers displays." These are simple low-to-high rate displays that permit travel agents to base decisions purely on price.

These displays list car rental firms based on the rates they offer for a particular type of car, for pickup at a specific location on a particular date and time, and return on a particular date and time. A standard coding system is used for various car types in the airline CRS, and most car rental firms try to categorize their car models according to this system. The displays typically show rates for rentals exclusive of insurance or such other services as ski racks and baby seats.

\section{Hertz is a wholly owned subsidiary of Ford.}

The increase in leisure demand has changed the market shares of rental companies (Figure 1). Today, both the commercial- and leisure-based firms seek a mix of commercial and leisure rentals to sustain growth and improve fleet utilization. Against this backdrop, Hertz began developing decision support tools like the following to help manage market changes: Fleet Planning System, Daily Planning and Distribution Aid, Cost Allocation Model, Competitive Rates System; and the Yield Management System.

In the 1980s, Hertz developed systems to support its decisions about rental fleet levels and the geographic redistribution of vehicles in response to shifts in demand. 


\section{CARROLL, GRIMES}
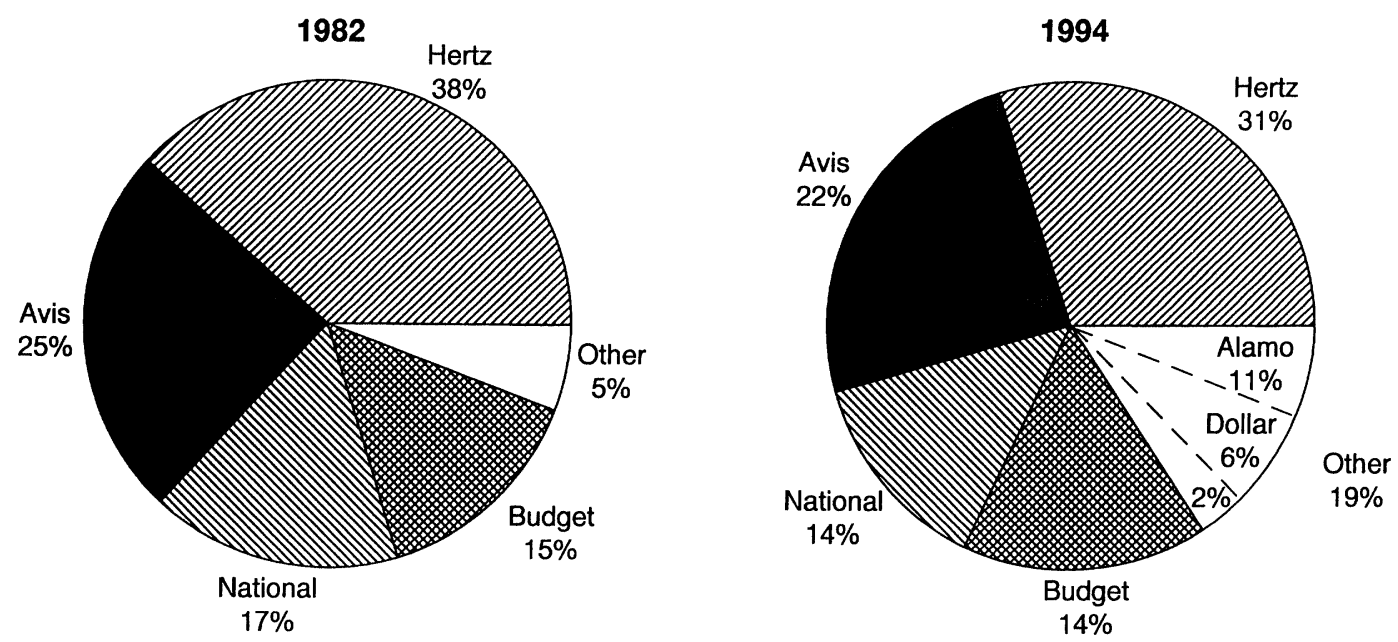

Figure 1: The airport market share of revenue has changed since 1982. Airline deregulation increased the demand for rental cars, especially in the leisure segment, changing company market shares.

For example, in major metropolitan areas, demand in downtown locations spikes on weekends as customers rent cars to pursue leisure or family activities. At airports, demand spikes mid-week in response to business travel requirements. These early systems were designed for use in areas ranging in size from major metropolitan areas with multiple rental offices at airport(s), downtown(s), and in the suburbs (collectively the multiple locations are called a pool) to smaller metropolitan areas with a single airport location. Typically the airport office makes decisions about fleet size for the entire pool and, of course, for smaller areas that have only one rental office or location.

The yield management system Hertz deployed in 1990 extended these systems and responded further to the emergence of leisure-based, low-priced entrants to the market. The challenge for Hertz was to compete on the basis of price for leisure business yet preserve and service its com- mercial contract business. An additional challenge was developing the capability to display various prices for its products in the internal reservation systems (Hertz reservation centers) and in the external ones (CRSs), where different display limitations exist.

Hertz has developed many of its various decision support systems over time to address four major strategic questions:

(1) How many cars should Hertz have?

(2) Where should it deploy those cars?

(3) What products should it offer? and

(4) What products should it sell?

\section{How Many Cars Should Hertz Have?}

Deciding how many cars one should keep in a pool or single-location fleet at any time is fundamental to successful car rental operations. The decision is complicated by three factors: the structure of car manufacturers' purchase plans; disposing of used cars through retail car sales or through wholesale (auction) markets; and the need to meet customer demand for 
particular types of cars. Typically, customer demand for different types of cars does not match the least costly mix of cars that could be purchased from the manufacturers. The most desirable cars for retail sales and car auctions also match those demanded by rental customers. Consequently, meeting customer demand for particular car types must also balance holding costs by car type, manufacturers' production schedules, and retail and wholesale car sales needs.

Hertz makes decisions about fleet size and composition at two organizational levels. It must make corporate decisions about overall fleet size and composition to negotiate effectively with manufacturers and to arrange financing. Given those decisions, it then makes decisions about long-term fleet size and composition and near-term fleet planning adjustments for the pools and single location operations.

From a purely economic standpoint, Hertz can base decisions about fleet size on contribution, defined as the difference between a car's expected revenue generation above the transaction costs and the car's holding costs over a given period. A car should be added to a fleet as long as its contribution over its operational life in the fleet is positive.

The models Hertz uses to establish optimal overall fleet levels are basically a set of linear equations that use historical rental information, the number of customers turned away through the reservation system (called turndowns), and estimated fleet utilization to produce aggregate fleet requirements. In Hertz's fleet planning system, the focus shifts from deriving the optimum to the use of these equations to forecast

-Utilization, the percent of the fleet "on rent" in customers' hands per month; -Turndowns, the expected number of customers to be turned away;

-Vehicle costs that include such holding costs as depreciation and interest, estimated both individually and through a separate business planning model; and - Revenue per car per month, the expected average revenue as estimated through the business planning model. These four variables are estimated overall and for pool and smaller individual fleets. Hertz does not exclusively use fleet levels that are optimal from a purely economic perspective, because from a strategic standpoint, it may sacrifice short-term contribution to maintain market share, encourage customer loyalty, and ensure dependable service-three factors that can provide long-term profitability.

Hertz's fleet planning models began as spreadsheets. These tools have evolved to permit Hertz to better evaluate the tradeoff between contribution and market share: To what extent must Hertz offset maximizing short-term contribution to expand its share of market revenue in order to sustain

\section{Demand in downtown locations spikes on weekends.}

longer-term market prominence and profitability? It makes decisions to maintain excess cars (overfleeting) or shortages (underfleeting) relative to these estimated requirements using forecasts of the number of cars on-rent by day into the future (car onrent patterns) and taking into account its 
current revenue share position in a given market (Figure 2). Over a planning horizon extending up to 18 months into the future, Hertz makes decisions to vary its fleet size. In the near term, it can vary the fleet size by accelerating or decelerating acquisitions or deletions or by diverting deliveries to other pools or locations. It must make purchase commitments for the overall fleet with manufacturers 12 months in advance. It now bases these decisions on direct feeds of demand forecast information from the yield management system forecasting modules, including

- The forecasted demand for the fleet, assuming Hertz serves all customers at competitive prices, or unconstrained demand; and

-Forecasted rejected demand, assuming Hertz maintains a selected fleet level at various times during the planning horizon. While rejecting demand may provide short-term profits, it also adversely affects the retention of customers and service levels (service is defined in terms of waits for a requested car or car type that is not available).

\section{Where Should Hertz Deploy Its Cars?}

Hertz developed the system to support decisions about the optimal distribution of cars because it needed to better manage the movement of cars within a pool. The decision to move cars among locations within a pool is driven by the patterns of demand for each city. Because demand at different locations can peak on different days of the week, managing movement improves utilization and revenue for the pool, although it may reduce the profitability of a particular location.

Hertz uses the current distribution model, the Daily Planning and Distribution Aid (DPDA) [Edelstein and Melnick 1977], almost exclusively at the pool level. A significant source of complexity is its active rent-it-here and leave-it-there program. DPDA uses actual information about cars on-rent, reservations for pickup in the future, and recent historical rental information about movement of rented cars both within and between pool cities to create movement distributions that it uses to fore-

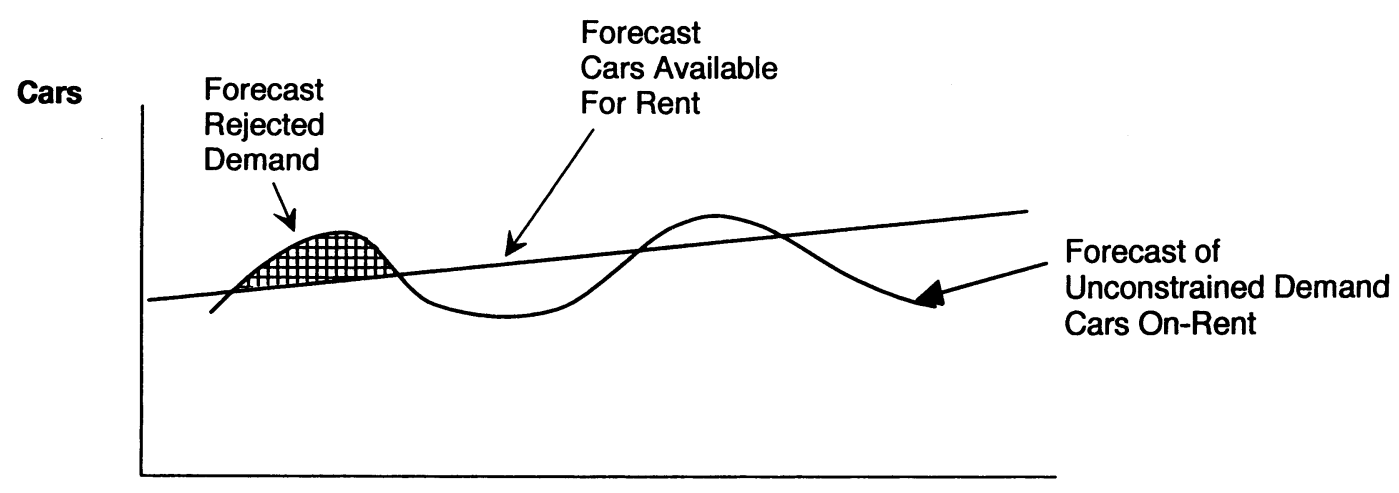

Future Days

Figure 2: Cars on-rent versus available fleet: A typical car on-rent pattern by day quickly identifies days with excess demand. 
cast future vehicle returns or check-ins.

DPDA applies its forecasting capabilities in conjunction with projected new fleet deliveries and deletions, interpool moves made at the direction of management, idle vehicle counts, maintenance shop counts, and history-based forecast information to predict dates when each location in the pool will be oversupplied or undersupplied with cars.

Interpool moves are less frequent than intrapool moves, and decisions regarding such transfers are made at intermediate and corporate levels. Generally, these moves are necessitated by a major event, such as the Super Bowl; an emergency, such as a natural disaster; or the need to rebalance the overall distribution of fleet by returning vehicles to "owning pools."
In making interpool move decisions, Hertz uses aggregate data from a pool-level DPDA, nationwide fleet tracking, and estimates of improved contribution despite the costs of moving vehicles.

DPDA relies on key variables, which are either input by the user or estimated for the user for each pool location during the planning period (Figure 3). For the first day of the planning period for each location, the user enters an actual count of idle cars (starting idle); subsequently, the DPDA derives this value. Then, the user enters projected net fleet additions and deletions (net adds/deletes), net vehicles scheduled in and out of maintenance (net shop), intercity transfers, and a forecast of future rentals. Given the expected drop-off locations of existing active rentals and patterns for

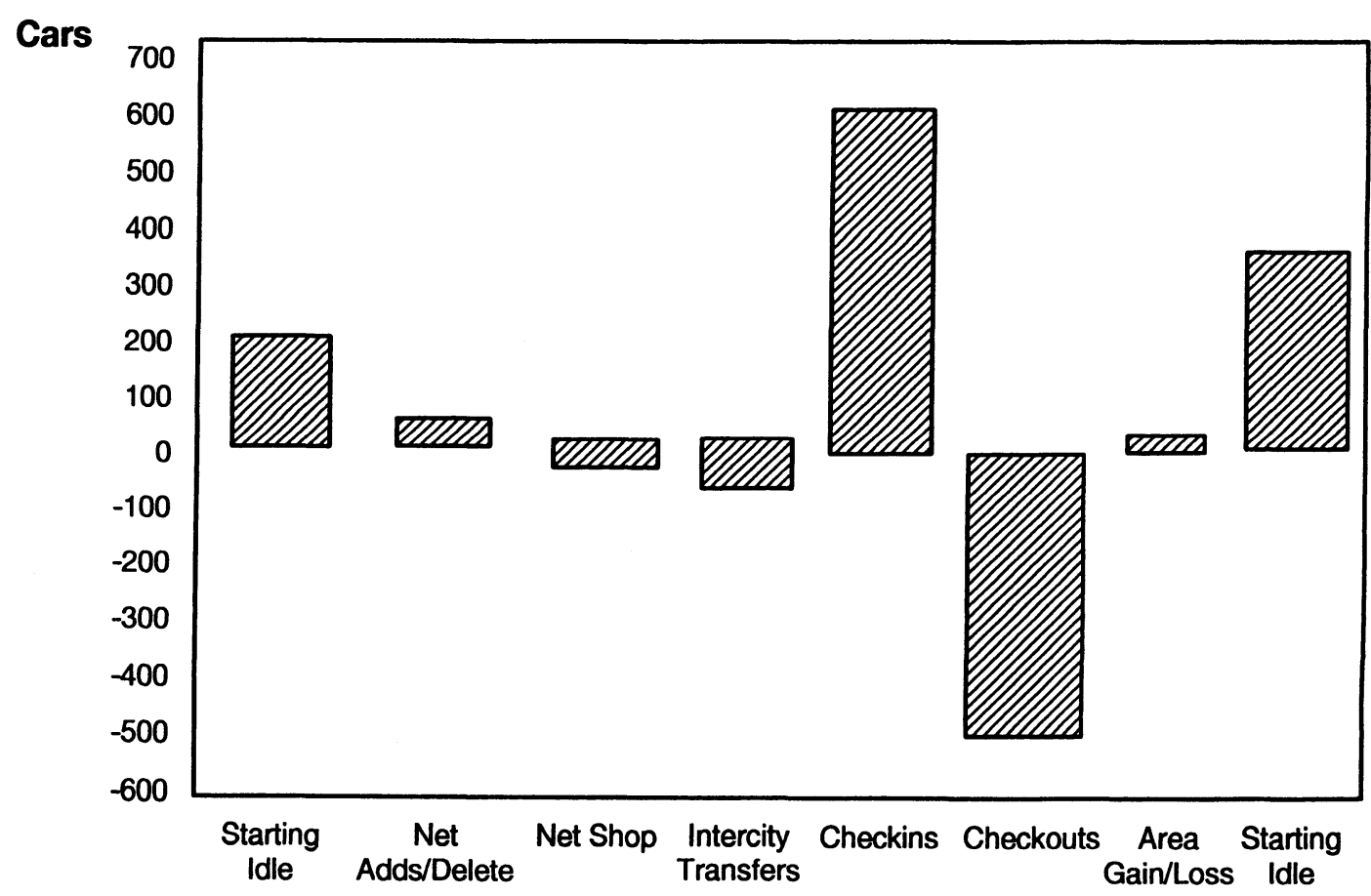

Figure 3: The fleet distribution model uses this underlying logic to calculate car availability for each location in a pool whenever forecasts change. 
future booking forecasts, the system derives estimated vehicle returns (check-ins) and shows the number of cars at each location each day. The user can evaluate alternative scenarios by varying each of the input variables. Using these simulations, users can produce alternate forecasts of each location's fleet levels for the purpose of fleet balancing. Users at independent or single location cities can also use DPDA to predict future fleet shortages or imbalances and, in response, accelerate fleet additions or deletions or visits to the maintenance shop.

\section{What Products Should Hertz Offer?}

Rental car products are designed to meet the diverse needs of leisure and commercial customers. For commercial customers, Hertz provides fast, efficient car rental service for individual customers, 24-hour road service, liability protection, and efficient accounting for the client enterprise-at a competitive price. Corporate contracts usually require Hertz to make the corporate rate available if it has the type of car requested. For leisure customers, Hertz provides a competitive rate for the size and style of vehicle needed, along with such related services as driving directions and 24-hour road service. Additional services, such as extended liability protection and loss or damage waivers, are available at a slightly higher price. The important distinction between these two broad types of markets is that Hertz can vary the base price (exclusive of additional services) to leisure customers based on market supply and demand conditions.

To segment commercial market customers from those in the leisure market, Hertz can invoke certain conditions, such as an advance reservation or a requirement that the car be kept over a Saturday night. These conditions or "fences" allow Hertz to offer price discounts for leisure customers in trough periods like weekends, without diluting the prices paid by commercial or midweek renters, whose demand is the primary driver of fleet costs.

Critical in developing products for both markets is the collection and comparison of Hertz's prices and its competitors'. Hertz's competitive rate collection system began as a manual system and has evolved into an automated canvassing device that polls CRSs and other sources regularly. It uses an artificial intelligence logic to align comparable competitive products with Hertz's (Table 1). It then scans the data to detect variances from strategic price gap targets by market and type of product. The report on competitive pricing is available on-line at headquarters and at field locations; it displays Hertz rates by car type compared with its major competitors' rates, along with the advance reservation required for the rate. The report is brought to the attention of headquarters pricing managers when the system detects a price variance outside the limits established by management (the limits represent a desired competitive price position in a particular rate segment-daily, weekly, weekend, or monthly). They can then decide whether to change rates.

In developing its products, Hertz managers also need to understand contribution by product and by mix of products. Hertz developed a cost allocation model that can evaluate the contribution provided at the product, account, market segment, and location levels. A client-server computer ar- 


\begin{tabular}{lllllll}
$\begin{array}{l}\text { Advance } \\
\text { Reservations }\end{array}$ & $\begin{array}{l}\text { Hertz } \\
\text { 2 Hours }\end{array}$ & $\begin{array}{l}\text { Avis } \\
\text { 0 Day }\end{array}$ & $\begin{array}{l}\text { National } \\
\text { 0 Day }\end{array}$ & $\begin{array}{l}\text { Budget } \\
\text { 1 Day }\end{array}$ & $\begin{array}{l}\text { Alamo } \\
\text { 0 Day }\end{array}$ & $\begin{array}{l}\text { Dollar } \\
\text { 0 Day }\end{array}$ \\
\hline EXAR & 27.99 & & & 26.90 & 26.99 & \\
ECAR & 29.99 & 27.99 & 31.97 & $36.90-\mathrm{HO}$ & 26.99 & 33.00 \\
CCAR & 32.99 & 32.99 & 34.97 & 31.90 & 31.99 & 33.00 \\
ICAR & 36.99 & 36.99 & 36.97 & 35.90 & 35.99 & 35.00 \\
IDAR & 36.99 & & & & & \\
SCAR & 40.99 & 40.99 & 39.97 & 39.90 & 39.99 & 37.00 \\
FCAR & 43.99 & 43.99 & 42.97 & 42.90 & 42.99. & 37.00 \\
PCAR & 52.99 & 49.99 & 48.97 & $59.90-\mathrm{HO}$ & & 40.00 \\
LCAR & 55.99 & 55.99 & & $60.90-\mathrm{HO}$ & $49.99-\mathrm{D} 1$ & 43.00 \\
SFAR & 61.99 & 55.99 & & & & 59.00
\end{tabular}

Table 1: A competitive price report shows Hertz's prices and those of its competitors.

chitecture with a graphical user interface provides this information to decision makers throughout the organization, including marketing, sales, finance staff, and field operators.

\section{What Product Should Hertz Sell?}

Since the industry began, car rental firms have used rudimentary mechanisms to control product availability, such as "blackout periods" during major events like the Super Bowl or the Olympics, or seasonal surcharge periods. These control mechanisms became more formalized at Hertz when the offsell system was introduced as part of the reservation system rewrite in 1980. This system provides Hertz managers with the ability to turn off reservations for a specified set of products that could range from all cars to all mid-sized cars to any car with a special feature (like a ski rack) on a particular date. In 1982, Hertz added a rudimentary capacity management system (CAPS). CAPS allowed managers at various levels in the organization to set maximum levels of availability for particular rates and car types. When Hertz reached these maximum booking levels, the system posted a nonavailability or offsell status to internal and external reservation systems. However, CAPS lacked information about car supply and about the impact on revenue of the prescribed capacity controls.

\section{Integrating Strategic Decisions with Yield Management}

In 1989, Frank Olson, chairman and CEO of Hertz, and Craig Koch, now chief operating officer, engaged Decision Focus Incorporated (DFI) to apply operations research and computer science techniques to design, develop, and implement a state-ofthe-art revenue or yield management system (YMS). Similar to an airline's yield management system, it integrated both supply and demand information. However, from the project's start, Hertz decided not to adapt existing airline yield management technology. While yield management has its origins in the airline industry, its application for car rental is more complex. Car rental systems must deal with a more migratory inventory, a more decentralized management of inventory, and a larger set of customer options than 


\section{CARROLL, GRIMES}

do airline or hotel yield management systems (Table 2).

In fact, because maniging yield was so complex in the car rental industry, Hertz had to decide how to handle the large array of car types. Cars range in size from a two-door subcompact to a four-door luxury model. They also vary in style, including convertibles, four-wheel drive vehicles, mini-vans, and sports cars. Ultimately, Hertz established groupings among vehicle types so that it could handle cars with special styling features differently for yield management purposes.

Conceptually, yield management integrates the four major strategic decisions Hertz faces. These decisions are linked [Boyd and Phillips 1992]:

(1) In planning its fleet levels, given infor- mation about the marginal value of an additional car, how should Hertz purchase and dispose of cars over time?

(2) In deploying its fleet, given information on the total available fleet and the marginal value of deploying an additional car at a location, how should Hertz deploy cars within a pool?

(3) In managing revenue or yield, given the available fleet by location, the product offering, and the business environment, what mix of product availability will provide the maximum net revenue for Hertz? (4) Given the marginal cost of offering more of a particular product and the competitive environment, what mix of services should Hertz offer?

Because of these conceptual linkages, Hertz designed the yield management sys-

\begin{tabular}{|l|c|c|c|}
\hline $\begin{array}{l}\text { Varying Complexities } \\
\text { among Airlines, Hotels } \\
\text { and Rental Cars }\end{array}$ & Seat & Room & Car \\
Inventory & $1-3$ & $1-10+$ & $5-20+$ \\
Number of Unit Types & Fixed & Fixed & Variable \\
Total Units By Location & Small & None & Considerable \\
Mobility of Inventory & Many (3-7+) & Few (2-3+) & Many (4-20+) \\
Rates Per Unit & Fixed & Variable & Variable \\
Duration of Use & No & Yes & Yes \\
Corporate Discounts & Central & Central/Local & Central/Regional/ \\
Local
\end{tabular}

Table 2: This comparison of yield management applications highlights some of the reasons why Hertz chose not to adapt existing airline methodologies for its yield management system. 


\section{CAR RENTAL}

tem from the start to be integrated with its other decision support systems for fleet planning, for daily planning and distribution, for product offerings, and for cost allocation. Information about the total available fleet is input to the yield management system through automated snapshots from the fleet planning system that describe anticipated fleet acquisition and disposition. Information about available fleet by location comes from anticipated fleet movements from the daily planning and distribution aid. The YMS takes data about product offerings from the Hertz "rate engine" that specifies the different types of products, their rates, and their restrictions.
From a systems perspective, this is how the various information flows are integrated into the Hertz YMS (Figure 4). The Hertz counter system provides a daily feed to the YMS describing recent check-outs, check-ins, and no-shows. The Hertz reservation system passes to the YMS all recent bookings and cancellations as well as any non-YMS availability restrictions. The system uses accounting information about various cost categories, in conjunction with a YMS activity-based cost model, to establish the variable costs of rentals so that it can consistently evaluate rentals of different products for different lengths of time. The YMS also passes some of its results to

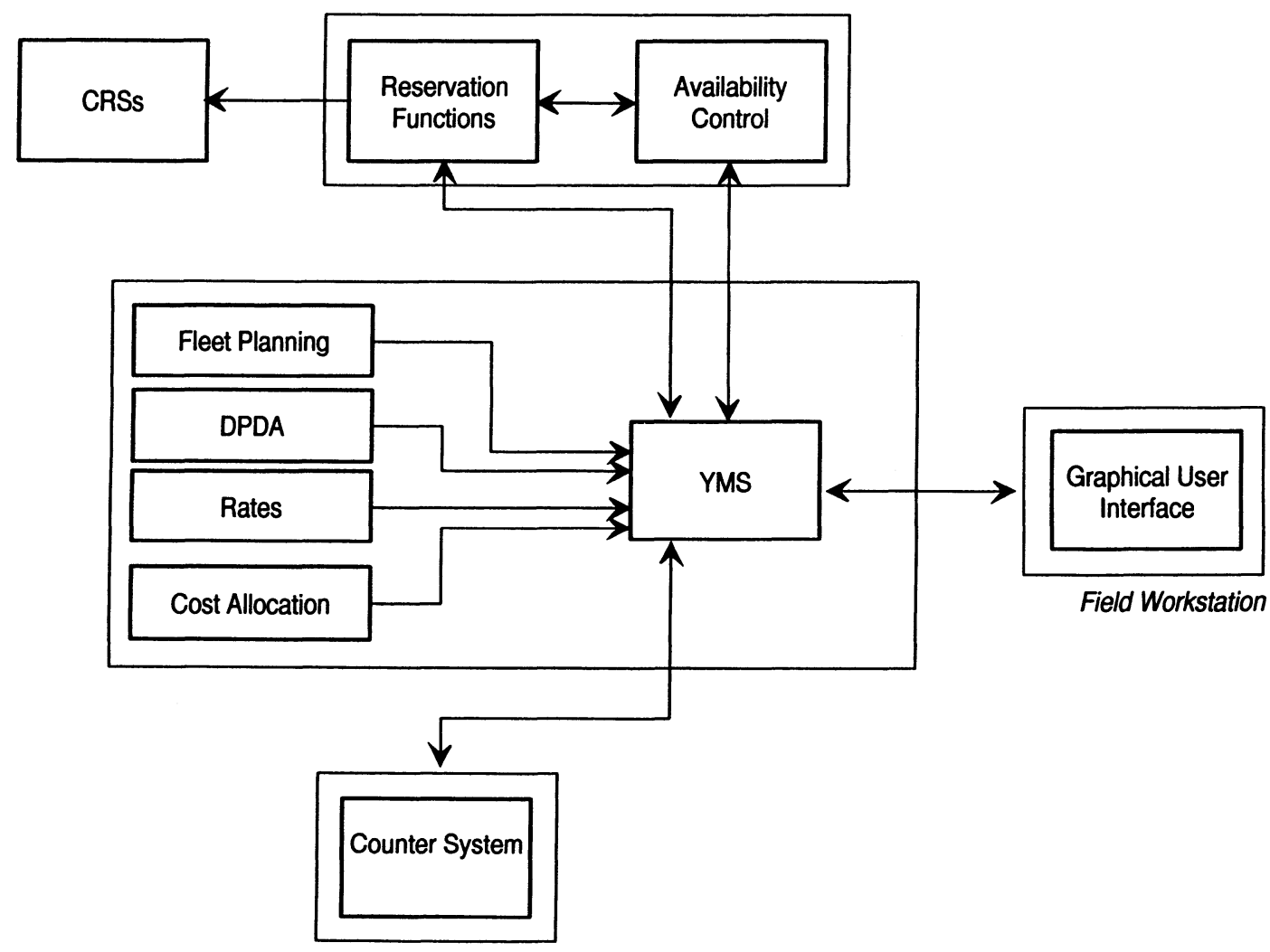

Figure 4: The yield management system integrates data from many other Hertz information systems and provides field personnel with a graphical interface for working with it. 
other Hertz systems. It feeds the reservation system availability restrictions that turn off availability by city, pickup date, car type, rate code, and length of keep. Users choose which of these to implement after reviewing the YMS recommendations through a graphical user interface. The YMS also feeds the fleet planning system and the DPDA its forecasts of rental demand.

\section{Rental Car Yield Management at Hertz}

The rental car product is a perishable product on any specific pickup date. However, the product is perishable in a strict sense only for the single day of pickup. An unrented car can be used the following day if demand is sufficient. In some instances, Hertz can generate more revenue by saving a car to meet demand on a future date. Customers' varied duration of use also affects the demand for and supply of cars. A car rented for three days is not available until it is returned, and its actual return may turn out to be in two days, or it may be in five days. A car may not be returned to the same location from which it was rented. The Hertz YMS creates, updates, and uses probability distributions on the actual amount of time the car was kept by the customer (length of keep), given the rental length specified at reservation time. This allows the YMS to represent the approximately 10 to 20 percent of customers who change their length of keep after booking. As an additional output, the YMS provides statistics that monitor attempts by customers to circumvent the conditions set by the YMS for a rate by length of keep. Using such information, efforts to circumvent the system can be traced to particular market segments (for example, leisure ver- sus commercial, customer-booked versus travel-agent-booked, and so forth). Once these segments are identified, Hertz can take actions to eliminate violations or alternatively to calibrate the YMS to account for such activity.

The YMS forecasts the capacity of cars available for rent at each location. These locations can be independent or part of a multi-location pool. To establish this capacity, it combines the results of two of the strategic decision processes: long-range fleet planning and short-range fleet deployment. These fleet planning decisions provide quantities for cars and approximate dates for acquisitions and deletions. Management decides on the basic fleet level about a year in advance of rentals, but can make changes about 90 days ahead. Hertz sets the specific dates for fleet acquisitions and deletions 90 to seven days in advance of the deliveries. Decisions to deploy the existing fleet--to move cars from one location to another-are much shorter term and have a stronger impact on the YMS.

Sometimes balancing the fleet within a pool is straightforward. For example, airport locations that serve New York City have midweek demand peaks; Manhattan rental locations have demand peaks on weekends. Cars are transported from the airports to the city locations on Thursdays and Fridays and returned to the airports at the beginning of the week. Within pools, decisions to transport cars from one location to another must take into account the issues of market share, service level, and trade-offs between the incremental revenue available from renting the car at another location and the cost of transporting 
it. The YMS provides baseline information to users making this decision by forecasting the projected revenue to be generated or rejected at each location. The decision maker must evaluate other variables, such as transport costs, service levels, and market revenue, using that information.

Hertz segments the market by offering products with differing services, prices, and restrictions. The car rental industry has been less successful than the airlines and some hotels at segmenting customers by requiring advance reservations. However, beginning in the late 1980s, Hertz has successfully used Saturday over-keep and weekend rates to stimulate demand from Thursday noon through Monday, when demand from commercial customers declines.

Hertz is able to segment demand between commercial and leisure customers by type of car, by financial protection coverage, by response to price, by length of rental, and by day of pickup. Commercial customers typically select mid- and fullsize vehicles; have financial protection for their firm included in the rate; are not paying for the rental themselves; and rent on weekdays for shorter time periods. Leisure customers are willing to drive smaller cars (or want specialty vehicles like vans and convertibles); are more apt to need financial protection for themselves; are paying for the rental themselves; and rent over weekends and for longer periods of time. The Hertz yield management system supports separate leisure and commercial products. It limits the availability of low leisure rates on days when cars are in short supply. It identifies opportunities when advance reservation low leisure rates should be limited to meet demand for near term commercial rentals at higher prices.

The Hertz YMS includes a comprehensive demand forecasting system. Each day it creates forecasts of unconstrained demand-the total possible rental demand independent of actual fleet levels. It makes separate forecasts of gross booking demand and cancellations. It varies the forecasts by the time prior to the pickup date and makes them for each city, pickup date, bucket (a set of similar products producing similar revenue), and length of rental. The forecasts also distinguish between those customers who reserve in advance and "walk-ups," customers who walk up to a Hertz counter on the day of pickup without a reservation.

To establish the revenue-maximizing set of marginal values and availability restrictions, the Hertz YMS combines two separate forecasts that have very different characteristics. One estimate of demand is based on historical demand for that date modified by user-supplied assessments of changes in the business environment. This history-based estimate provides stability and is generally more accurate than other

\section{Hertz makes decisions to vary its fleet size.}

estimates far in advance of a pickup date and for nonstandard dates, such as holidays. The second estimate is produced by a Bayesian updating model that uses recent observations to update a prior forecast that reflects the pace of bookings and cancellations over the previous one to two months. The model incorporates techniques to 
avoid updating the prior when availability restrictions limit the bookings for a particular bucket. It applies other techniques to buckets for which future booking demand is high that have been found to increase forecast accuracy. The YMS combines the history-based and bookings-based forecasts to produce a forecast whose standard deviation of error is lower than that of either separate forecast. Periodically Hertz determines optimal weights for combining

\section{Interpool moves are necessitated by a major event.}

the two forecasts by comparing historical forecasts and the corresponding outcomes. The YMS makes forecasts at a very detailed level, specifying expected future net bookings for a particular city, day of the week, bucket, length of rental, and time prior to pickup. Because we needed this level of detail, we did not use such traditional forecasting methods as Box-Jenkins, which proved less accurate.

We incorporated user-supplied forecast overrides in the YMS to allow users (normally local or regional managers) to use their local knowledge of the competitive situation. The YMS forecasts are stochastic and include distributions of forecast accuracy established by analyzing past forecast performance. Forecasts of constrained demand-limited by the fleet available for rental-incorporate estimates of the willingness of different customers to buy-up, that is, to agree to a higher-priced car type or rate level if the one they desire is not available. These state-specific constrained forecasts are used by the revenue optimi- zation to describe a revenue surface over which to search for a global maximum over the entire planning horizon. The YMS can also convert all forecasts for rentals to projections of on-rent patterns for use in fleet planning and fleet deployment decisions.

The YMS sets recommended overbooking levels in a way that optimizes net revenue while maintaining a specified quality service level; this service level is measured in terms of the likelihood that a customer with a confirmed reservation will have to wait for a car. From Hertz's perspective, the customer should not have to wait more than a few minutes for a car. Because of its commitment to quality service, Hertz did not use the traditional airline approach of estimating and trading off the cost of a denied customer against the cost of having left-over fleet [Smith, Leimkuhler, and Darrow 1992]. Instead, we constrained the overbooking optimization by requiring that the likelihood of a customer with a confirmed reservation having to wait for a car or, worse, not being accommodated, is kept below a pre-specified, small probability. The YMS calculates the probability of various overbooking outcomes by convoluting distributions of future booking demand with "show" rates, using information about current booking levels and noshow forecasts.

The YMS calculates the set of product availabilities that maximizes net revenue using marginal values, sometimes called bid prices [Phillips 1994]. The objective function specifies the total net revenue over the planning horizon. The formulation also includes a set of constraints that limit the marginal values to a feasible set 
described by the city's available cars over the planning horizon. The solution to this problem provides for the optimal set of marginal values, one for each pickup date. The time periods used by the YMS optimization are different from calendar pickup dates; the marginal values reflect the supply/demand trade-off at the peak hours of the day at each location. Peak hours vary by city and result from hour-by-hour patterns of pickups and returns often determined by airline schedules.

The marginal values also serve as a very concise shorthand that describes hundreds or thousands of revenue-maximizing product availabilities. Since the YMS looks at the revenue generated over the entire planning horizon, it is possible that alternative product availabilities could generate more revenue on a single pickup date. However, the proper longer-term perspective the YMS provides helps Hertz to avoid unprofitable short-term decision making.

The Hertz YMS revenue optimization solves a nonlinear stochastic problem using as primary inputs forecasted distributions (mean and standard deviation) of future net booking and walk-up demand and the corresponding rates over the economically sensible set of marginal values or availability scenarios; predicted fleet levels available to serve future demand; and the recommended overbooking levels calculated using forecasts of cancellation and noshow rates. The explicit uncertainties incorporated into the model include the accuracy of the booking forecasts, the walk-up forecasts, and the no-show rates.

The marginal values are the dual variables of a traditional airline revenue management formulation solving for autho- rized levels by booking class. A marginal value represents the minimum net revenue Hertz is willing to accept for a one-day rental on that date. In the car rental industry, marginal values are a more effective way to optimize net revenue than calculating authorized levels. They allow rental companies to calculate availabilities by length of rental in a straightforward way, without requiring complex nesting structures that prespecify product desirability. They also allow the optimization to take

\section{Hertz can vary the base price to leisure customers.}

into account the limitations on yield management that corporate contracts impose, making the rate available if the type of car requested is available. The optimization uses net revenue- total revenue less variable rental costs that are determined using a simple activity-based cost model-to evaluate rentals of different lengths correctly. Because the variable rental costs are associated with the rental transaction itself, three one-day rentals are usually not as profitable as one three-day rental.

Because field personnel understand marginal values and the YMS replicates how they think about the problem of determining product availability, its implementation was smooth. The YMS converts optimal marginal values to optimal product availability recommendations for review by the YMS users prior to implementation (Figure 5). Field personnel accept or reject these YMS bucket availability recommendations that compare the expected net revenue generated by each bucket to the marginal 


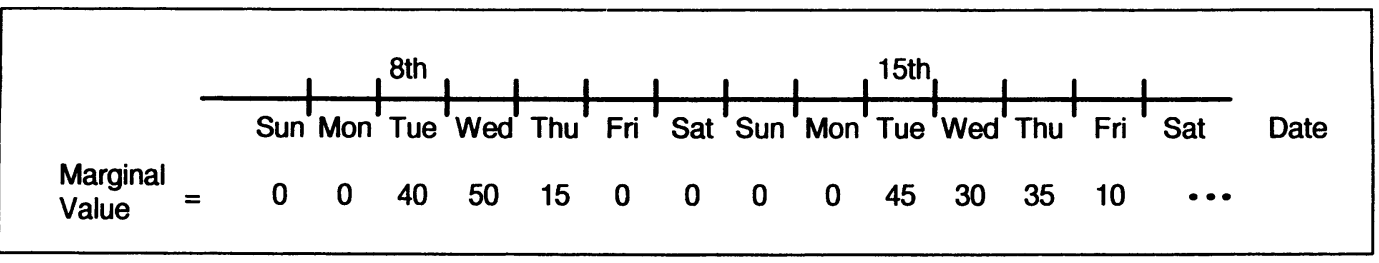

For rental on Tuesday the 8th:

$40 \quad 50$ Accept 2-day rental if Net Revenue $>\$ 90$

$\begin{array}{llll}40 & 50 & 15 & 0\end{array} \quad$ Accept 4-day rental if Net Revenue $>\$ 105$

For rental on Tuesday the 15th:

$45 \quad 30$ Accept 2-day rental if Net Revenue $>\$ 75$

$\begin{array}{llll}45 & 30 & 35 & 10\end{array}$ Accept 4-day rental if Net Revenue $>\$ 120$

Figure 5: Marginal values for each pickup date are derived by the YMS optimization. Managers review the marginal values and the corresponding availabilities by pickup date, bucket, and length of rental.

values that represent the opportunity costs of the available fleet.

When field personnel implement their availability decisions through the YMS to the Hertz and external CRS, Hertz reservation agents or travel agents can sell or confirm booking requests only for the products that are available. The travel agent, using a CRS screen, can also see the availability status of each product-sell (s) or closed (c).

The YMS system shows users a set of easy-to-use displays that allows them to understand its recommendations and execute them. Local city managers, regional managers (who are responsible for multiple pools), and headquarters managers have access to the system. Each of these managers can view various user screens, and those authorized to do so can enter data and execute actions. Maintenance and central (headquarters) control and monitoring functions are also available in the system. This functionality and the screen design are critical and proprietary parts of the Hertz YMS.

Yield Management System Development

Hertz based its early methodologies for planning its fleet and its distribution in the 1980 s primarily on the operational needs of the field and the available information system infrastructure. It built up its systems and the associated business processes for making decisions over a number of years. It added to systems, modified them, and reconfigured them without paying 


\section{CAR RENTAL}

much attention to the overall relationship among decisions or to the need for managing yield. The growing use of computers at Hertz reinforced the need for greater integration of business processes and systems. At the same time, rates and rate structures were becoming more complex and airline CRSs were better able to display them. This complexity prompted Hertz field managers to press for integrated planning systems starting with yield management.

In developing the yield management system in 1989, we tried to integrate a number of the existing systems and business processes, allowing the formerly separate systems to share consistent data. The YMS generates detailed demand forecasts and optimal product availability recommendations for future pickup dates using a wide variety of information from other Hertz systems. In developing and deploy-

\section{Car rental systems deal with a migratory inventory.}

ing yield management systems, we had the opportunity to integrate these systems and reengineer business processes and organization structures related to the four main strategic decisions [Gulden and Reck 1991]. In reengineering our goals, we were able to establish new cross-functional business processes that would support the generation of incremental revenue from the yield management system and to improve the performance of existing Hertz systems for fleet planning, fleet deployment, pricing, and product specification. To help us, we brought in outside consultants (DFI) who did not have a stake in existing systems or processes.

The commitment of senior Hertz managers was vital to the process. It was important initially to expedite the development process and later when deploying the system. At the outset, Hertz established a steering committee to facilitate the collaboration between Hertz and DFI. This committee included Hertz headquarters personnel, MIS department staff, key field personnel, and members of the DFI project team. The varied perspectives of the members of the steering committee provided DFI with a comprehensive understanding of Hertz's strategic goals and directions, field operations, and information systems, and made Hertz aware of some of the issues involved in developing and applying a yield management system. The committee also addressed five issues that arose during system development and implementation:

-Design of the graphical user interface; - Required enhancements to existing Hertz systems;

- Interfaces between the yield management system and other Hertz systems; - Review of the modeling approaches for demand forecasting, fleet forecasting, revenue optimization, and implementation of system recommendations; and - System rollout and user training.

One of our goals in developing the system was to minimize development time, costs, and risks. We faced challenges in two main areas. The first was developing sophisticated models for forecasting future demand and fleet size, optimizing total net revenue over the planning horizon, and applying YMS actions through the Hertz and airline reservation systems. Hertz was 


\section{CARROLL, GRIMES}

the first company to implement a yield management system that used a marginal value approach to revenue optimization. The second challenge concerned the architecture of the computer system. Yield management for car rentals is most successfully applied locally, at the city level, and at the pool level. To facilitate this local application, the YMS - primarily a batch, mainframe application-uses decentralized field workstations with graphical user interfaces to present information in an organized manner and facilitate use of the system. More than 100 cities use the Hertz YMS; all the city managers and the regional yield managers have field workstations. The field workstations also provide cooperative processing and on-line access to a mainframe database.

Another technique we used to develop the system and to improve user acceptance was rapid prototyping. DFI developed prototype forecasting modules and used them to analyze historical rental data and to evaluate alternative forecasting methodologies. Using these modules, we discovered two techniques that provided effective reservations-based forecasts and demonstrated the circumstances under which the use of each is preferable. DFI used prototype optimization programs to establish the nature of the revenue surface we needed to optimize. After the development team realized that traditional nonlinear optimization techniques would not ensure finding the optimum on the nonunimodal revenue surface, we used the prototypes to investigate the performance of home grown optimization approaches that explicitly accounted for the nature of the problem. By incorporating this sort of learning process into the development activities and by allowing for discovery during prototyping, a skilled DFI development team was able to provide greater functionality and more accuracy, while avoiding the potential pitfalls of unfocused development. As a result, we reduced overall development time and costs.

The graphical user interface also took advantage of rapid prototyping techniques, allowing a number of iterations among a wide audience of potential system users from city managers and regional managers to headquarters managers and executives. Once we had reached agreement about the design of the interface, we proceeded with system development and coding. We established external interfaces with existing Hertz systems, databases, and on-line functionality through formal design, development, testing, and implementation. This process took the development team of DFI and Hertz programmers and analysts about 18 months.

\section{System Implementation}

We also took advantage of the rapid prototyping approach in rolling out the system. Hertz chose a paced implementation over 12 months beginning in mid1990 for initial testing. The YMS evolved quickly as we gradually incorporated useful new features. For the initial testing, Hertz selected five cities whose characteristics represented those of most US cities. They included an independent commercial city, an airport that is part of a large metropolitan multi-location pool with mixed commercial and leisure demand, a major leisure location, and two airport rental locations that are part of smaller city-wide pools that have primarily commercial de- 
mand but also some seasonal leisure demand. We rolled the YMS out to the initial test locations over five months, so that we had time to evaluate and incorporate change requests made by users and by the steering committee. The initial roll out indicated that some capabilities required for a large independent city - which can include a very small, nonautomated location-were not needed for pool cities where typically all locations are large and automated. We needed different modeling approaches to forecast the movement of cars within a pool from one city to another and different business processes for pool distribution personnel than were required at independent cities. After the 12-month initial testing, Hertz rolled out the system to the remaining major US locations in three months.

\section{Maturing of the Yield Management System}

Hertz first deployed the yield management system in August 1990 and by July 1991 was using it in its largest 55 cities. The system has three groups of primary users. The first is regional managers who oversee multiple pools. They use the system to identify the dates of peak demand and to control product availability by limiting the number of discount products available during the peak and controlling them carefully for length of rental. They also stimulate volume during periods of low demand by making lower priced products available. Regional managers are generally responsible for determining the availability posture for future pickup dates during the six months to several days before rental.

Before Hertz implemented the YMS, regional managers spent a great deal more time canvassing competitive rates. They had only the DPDA system to help them identify future sellout dates and no automated tools to help them decide what availability restrictions to set. They implemented availability restrictions using a time-consuming manual process that included a lot of data entry. They now spend most of their time working with the YMS graphical user interface to review and refine the automated forecasts and the optimal availability restrictions. They also work with managers responsible for fleet and distribution to make decisions consistent with yield management.

The second group of primary users of the YMS is local city managers. They use the YMS to review forecasts, to control product availability, and to stimulate demand, when appropriate, during the few days prior to rental. Since their responsibilities include many other tasks, we designed the YMS to signal to them what pickup dates require attention.

The YMS graphical user interface uses a calendar screen to organize the results and provide users with an overview of a twoto four-month planning horizon. It uses various colors and shadings to indicate days that require management attention. For example, it shows days on which action must be taken to restrict availability due to excess demand (red) or to stimulate demand due to excess fleet availability (green). From this screen, the user can select a specific date using a mouse. For the selected date, the program then shows detailed information about forecasts or availability recommendations. Users take action by entering overrides or inputs to the demand or fleet forecasts, or by implement- 
ing desired availability recommendations one day at a time, sending availabilities directly to the Hertz CRS. The system provides help screens throughout the user interface. These are referenced to the users' current screen position and available through an index system. The system also allows users to graph and view many key variables provided by the YMS. A diary function allows users to store pertinent information about dates for historical reference or communication to other users. This feature is particularly useful for managing availability around key events or holidays.

A third group of users is at the headquarters in fleet planning and pricing functions and in the field as regional fleet planners and pool distribution managers. The YMS helped improve communication between these headquarter departments and local region managers. Effective yield management requires information about fleet levels, fleet deployment, rates, and competitive response. More daily interaction now occurs between headquarters and field staff about the intertwined decisions required to plan the fleet, deploy the fleet, and manage yield. In fact, this interaction has created this third group of YMS users.

\section{The rental car product is a perishable product.}

Field and headquarters fleet managers now use YMS to plan the appropriate fleet levels 90 days to 12 months in advance; headquarters pricing managers monitor demand activity to highlight periods when Hertz needs to introduce discount products; and pool distribution managers di- rectly integrate YMS and DPDA use. The system provides a focus for the exchange of information that is necessary if managers are to coordinate their decisions rather than making them in isolation. The YMS focuses on the near-term impact on revenue of accepting or rejecting potential rentals. This allows managers to evaluate trade-off impacts systematically in making decisions concerning such issues as market share, service, and value.

Over the first three years of YMS usage, the primary focus was on integrated decision making and user training. Users of the system often went through three phases in understanding the application. At first, they were skeptical of the yield management system and its recommendations. The system differed from the manual and experience-based process they understood and introduced a variety of new terms and capabilities. We encouraged this skepticism as an important part of beta testing and user training so that we could prove to the users the value of the system and get their buy-in. Once they become confident that following the YMS availability recommendations well in advance of a pickup dateas soon as the sellout was identified-still resulted in a sellout, much of their resistance and operational concerns evaporated. They also realized that the system was making consistent economic trade-offs that increased their revenues. At one airport location where the Hertz employees could see the competitors' carwash operations cleaning cars after rentals are checked in, they noticed on a Wednesday sellout that one competitor was washing many more cars than they were. The YMS had recommended allowing very few one-day rentals 
the previous day, and therefore much of the demand for the less profitable one-day rentals had gone to the competition.

Once the users had accepted the system, we focused further training on integrating strategic decisions and improving the accuracy of the YMS inputs from other Hertz systems. We also wanted to use the YMS over an extended period of one to two years under a variety of circumstances and then evaluate its capabilities. We analyzed past dates over a six-month period extensively. We compared dates during tight fleet periods, when the YMS was used extensively, with comparable dates when the YMS was not used because Hertz had excess fleet. With enough data we were able to dampen the random noise found in demand outcomes. Comparisons of the average revenue per rental during these two periods indicated incremental gains through the use of the YMS of one to five percent, with the range due to variations among cities with different competitive environments and pricing and the magnitude of the sellout periods. Greater incremental revenue is possible when Tuesday through Thursday are sellout days, instead of only Wednesday.

Users came to appreciate the system as a tool that simplified abstract rental car operations through mathematical manipulation. Experienced users come to appreciate what parts of the system perform best and what parts are more sensitive to input values or assumptions. For example, users can use the system to manage major market changes, such as airfare wars, special events, and large changes in the business environment like those introduced by the Gulf War; however, the system remains sensitive to the accuracy of the forecasts of future fleet levels.

\section{Looking to the Future}

In improving the yield management system, we expect to take three steps. First, we plan to refine the model formulations for forecasting demand and fleet to improve their accuracy. Hertz also plans to enhance the system's ability to monitor and measure performance to provide users and headquarters personnel with better feedback.

Second, we plan to enhance the decision support systems for fleet planning and fleet deployment. Hertz has already taken great strides in understanding the interrelationship between supply and demand for cars over the short and long term. Car makers have recently increased their prices on cars for rental car companies and extended the required holding period from four to six months. It is more important and valuable than in the past that Hertz plan its fleet correctly. By building new tools and enhancing existing models, Hertz will be better able to utilize YMS results and more accurately make the profit and share tradeoff. These improvements will explicitly integrate the fleet planning, fleet deployment, and yield management decisions.

Third, we have to deploy the strategic decision support systems we have developed in the US to Hertz's world-wide operations. This will be challenging. Different countries have very different cultures, customer expectations, business and information system environments, and competitive situations. In Europe, for example, there is a greater dispersion of car rental locations to support rail than in the US. Also, some non-common market countries have re- 


\section{CARROLL, GRIMES}

strictions on rent-it-here leave-it-there operation. Careful analysis and preparation will be needed to determine the specific requirements and needs for decision support tools. Only then will we modify and deploy the models and train users so they can use them to solve their business problems and obtain the anticipated benefits.

\section{References}

Boyd, Dean and Phillips, Robert 1992, "Integrated transportation planning," paper presented at the ORSA/TIMS Conference, San Francisco.

Edelstein, Marty and Melnick, Myron 1977, "The pool control system," Interfaces, Vol. 8, No. 1, Part 2, pp. 21-36.

Gulden, Gary and Reck, Robert 1991, "Combining quality and reengineering for operational superiority," Indications, Vol. 8, No. 1, pp. 1-9.

Phillips, Robert 1994, Proceedings of the 16th IFIP Conference on System Modeling and Optimization, ed. J. Henry, Springer-Verlag, New York.

Smith, Barry; Leimkuhler, John; and Darrow, Ross 1992, "Yield management at American Airlines," Interfaces, Vol. 22, No. 1

(January-February), pp. 9-30. 